\title{
An Empirical Study on Academic Capital of Faculty Based on the Academic Cooperation Network
}

\author{
Shuqiang Li a , Xiang Xie ${ }^{b}$ \\ School of Beijing Jiaotong University, Beijing 100043, China \\ atdlsq1991@126.com, bxiangx@126.com
}

\begin{abstract}
This paper examines the factors influencing the academic capital of university teachers by studying the three subjects' teachers data of a university, and focuses on the study of the learn edge structure influence on the academic capital. And through the analysis of teachers' academic cooperation network in the academic capital to further explore the impact of various factors, the results showed that: professor papers published more than associate professor and lecturer, associate professor paper published by first author have a higher number. The highest academic degree has a great influence on academic capital. Professional background have impact on output, engineering professionals have a higher academic capital. Undergraduate learn edge structure have a smaller impact on academic capital, and the master structure has a positive impact.
\end{abstract}

Keywords: learn edge structure; professional background; the highest degree; academic capital.

\section{基于学术合作网络的高校教师学术资本实证研究}

\author{
李树强, 谢祥 \\ 北京交通大学, 北京 中国
}

摘 要: 本文通过某高校内理工商三个学科的师资数据, 考察影响高校教师学术资本的因素, 重点研究了学缘结构对学术资本的影响。并通过分析教师学术合作网络中的学术资本进一步 探讨各因素的影响, 研究结果发现: 教授的论文发表总量高于副教授和讲师, 而副教授以第 一作者身份发表的论文数量较高。教师所获得最高学位对学术资本有较大影响。专业背景影 响产出, 工科类专业的学术资本较高。本科学缘对学术资本影响较小, 而硕士学缘有积极影 响。

关键词: 学缘结构; 专业背景; 最高学位; 学术资本

\section{1. 前言}

学术资本是衡量教师科研水平的重要依据, 也是衡量一所高校学术状况的主要测度之一, 高学术资本的教师成为高校相互争夺的资源, 因此研究高校教师学术资本的影响因素, 并采 取有效的人事管理政策引导教师更多的学术资本是高校人事改革的重要内容。影响高校教师 学术资本的因素不但包括个人因素, 还包括一些外部环境因素, 在影响因素研究过程中, 教 师的学缘关系尤为引起研究和实践的广泛关注。一方面, 国内高校做出相应的改革限制本校 学生留校, 学术近亲繁殖被认为不利于学术创新, 会降低教师学术资本绩效 [1]。

而另一方面，高校在教师招聘环节非常重视学缘关系，尤其对 “985”高校毕业生的偏好 已成为普遍的潜规则, 国内高校之间的毕业生流动存在显著的区域性特征, 知名大学之间没有 形成一个师资交换圈 [2], 这现实状况之间的矛盾表明对学缘关系影响的研究仍然不足。大多 数研究以定性为主, 尚缺乏更有力的实证支持。在变量解释上, 主要是基于毕业生留校这一 单一学缘关系, 忽略了多层学缘关系共同作用的效果, 也未能考虑不同学术经验下学缘关系 影响的差异性。 
本文在控制相关环境因素的前提下, 研究多层学缘关系对学术资本的结构性影响。同时, 本文引入学术资本的概念来进一步探讨学缘结构的差异性, 在之前有些学者利用社会网络分 析方法中的社会资本理论来衡量个体在社会网络中所拥有的社会资源基础上, 改进社会资本 的计算方法, 利用学术合作网络分析个人的学术资本, 并进一步研究学缘结构对学术资本的 影响。这一研究对高校人事管理的意义在于制定更有针对性的教师笁选和学术评价机制 [3]。

\section{2. 研究内容}

考虑到学校规模等环境因素对学术资本的影响, 本文调查选取同一所高校内的理工商三 个学科的415位教师作为样本。该校属于教育部直属重点高校, 所选取的数据有一定的代表性。 样本的数据资料来源于该校官方网站, 由于受公布信息限制, 教师的数据存在着缺失值, 本 文所有的分析都是在剔除缺失值前提下进行的。在衡量教师学术资本时所用的论文数据包括 国内论文和国外论文两大部分, 其中国内论文数据通过CNKI数据库进行检索, 国外论文数据 来源于SCI和EI数据库，所检索获得数据时间截止于 2016 年 8 月 1 日。

高校教师之间的学术合作主要通过论文、专著、专利和项目等方式展开，因此本文利用 高校教师所发表的国内外论文来挖掘教师之间的学术合作关系。通过与其他科研人员在论文 撰写与发表活动中不断交流, 科研人员之间逐渐形成学术合作网络, 也在逐渐积累个体的 “学 术资本”, 而这种不断积累的个体 “学术资本” 必将会对学术资本有所影响, 因此若可通过 科研论文发掘教师之间学术合作网络, 分析教师的学缘结构是否会对个体的 “学术资本” 产 生差异，从而对高校人事改革政策做出更有利的支持 [4]。

科研人员为了使自己的科研活动更容易展开, 会积极的去获得学术资源, 积累 “学术资 本” , 因此我们使用社会资本理论来解释学术合作网络。通常情况下, 国外学者在研究个体 社会资本时更偏向使用职业声望来测量, 这一指标或许在西方更适用, 但在中国权力分数是 更为合适的测量社会资本的指标, 因为在中国社会认识有实权的人比认识职业声望高的人所 获取更多资源可能性更高 $[5]$ 。因此本文使用赵延东的权利分数表来测量教师的个体 “学术资 本”。

2.1. 个体学术资本的测量

若科研人员在学术合作网络中越易获得学术资源则更容易有学术资本，科研人员则通过 不断积累学术资本来获得更多的学术资源。有学者通过社会网中的职业权力分数来测量个体 的社会资本, 同样, 在学术网中也可以测量教师的学术资本, 因为教师职称的评定是与其学 术能力相关的, 上文分析得出教师的职称能在一定程度上代表教师的学术能力, 教师的职称 越高, 所拥有学术资源越广, 积累的学术资本越大, 因此可以用教师的职业权力分数来衡量 教师的学术资本, 若教师的职业权力分数越大, 则其学术资本越大, 学术资源越广, 即教师 的职称越高, 其职业权力分数越高。

由于以第一作者身份发表的论文更能代表教师的学术水平, 因此本文选取样本教师中以 第一作者发表的国内外论文数据, 进而分析教师的学术合作网络。若教师以第一作者身份发 表的论文与其他作者有合著关系则视两人合作一次, 双方合著的论文数量越多, 说明双方学 术合作次数越频繁, 相互之间的关系更加密切, 从而两者之间所积累的学术资本越大, 有学 者通过定位法将个体的社会资本用职业权力分数来衡量, 但是并没有考虑相互之间关系强弱 的权重, 本文利用作者之间的合作次数来表示科研人员之间的学术关系的强弱, 进一步改进 学术资本的计量方法。

通过软件bibexcel对样本中以第一作者身份发表的论文数据进行分析, 得出样本教师两两 之间的学术合作数据, 并通过ucinet对作者之间的合作网进行可视化处理（表1）。 


\begin{tabular}{ccc}
\hline 合作者 1 & 合作者 2 & 合作次数 \\
\hline 蔡** & 王** & 874 \\
蔡** & 刘** & 869 \\
简** & 宁** & 855 \\
$\cdots$. & $\cdots .$. & $\cdots .$. \\
\hline
\end{tabular}

赵延东通过对各种职业的调查分析得出大学教师的职业权力分数为46[6], 本文在前人的研 究基础之上按照职称对教师的职业权力分数进行划分, 目前教师的职称主要分为: 教授, 副 教授和讲师, 赵延东所得到是大学教师的职业权力分数, 那应该如何根据教师的职称不同给 其赋予权力分数呢? 教师职称对学术资本有一定的影响, 教师的学术资本与所积累的学术资 本深深相关, 因此可将不同职称教师所占的学术资本的比例作为权重对不同职称的教师赋予 权力分数。这样就可以测量学术合作网络中与个体有学术合作关系者的职业权利分数, 但是 这并不能体现作者之间的合作关系的强弱, 因此还要加入双方的合作次数作为权重来衡量个 体的学术资本。

综上，教师的个体学术资本是处于学术合作网络之中的，与之有合作关系的教师职称越 高, 且双方的学术合作关系越为紧密, 则个体的学术资本越高。

通过上文分析得出的教师之间的学术合作网络, 本文利用以下公式得出以下各教师的学 术资本:

大学教师学术资本 $=$ 大学教师职业权利分数 $\times$ 职称权重 $\times$ 合作次数。

2.2. 各因素对学术资本线性回归分析

通过上文分析可知, 学术资本越高代表教师越易获得学术资源, 从而有更多的学术资本, 因此分析各因素对学术资本的影响可进一步探讨各因素对学术资本的差异性, 本文通过以下 多元线性回归模型对各因素进行检验。

$\mathrm{Y}=\alpha+\sum \beta \mathrm{iXi}$

在这个模型当中, 解释变量Xi的含义为影响学术资本的诸因素, $\beta$ i 为解释变量对学术资 本的影响程度, 因变量Y为教师的学术资本（表2）。

表2 影响学术资本因素的回归分析（回归系数）

\begin{tabular}{cc}
\hline 影响因素 & 回归系数 (标准化) \\
\hline 性别 & -0.002 \\
专业 & 0.195 \\
最高学位 & -0.06 \\
学缘关系 & -0.128 \\
第一作者论文合计 & 0.359 \\
\hline
\end{tabular}

线性回归模型中对回归的显著性检验值 R方为 0.238 ，说明该回归模型有一定的解释性， 通过回归分析可以发现，

(1) 在控制了其他变量之后, 性别对学术资本有一定的影响, 女性教师的学术资本略低于男 性教师。

(2) 专业背景会对教师的学术资本有一定的影响, 工科教师的学术资本要高于商科和理科。

(3) 教师所获得最高学位与其学术资本成正相关, 若教师的最高学位越高, 在学术合作网络 中获得学术资本越高。

（4）教师的学缘关系也会对学术资本有所影响, 具体的影响将通过下面的分析探讨。

（5）教师以第一作者发表的论文数量会对其学术资本有正相关的影响，因为以第一作者身份 发表的论文则更能代表个人的学术能力, 第一作者作为学术合作网络的中心点, 以第一作者 身份发表的论文数量越多则他的网络规模越大, 所获得较多的学术资源可能性越高, 则其学 术资本越高。 


\section{3. 学缘结构对学术资本的影响}

从上文可知, 学术资本代表教师在学术合作网络中的可获得的学术资源, 因此可以通过 分析学缘结构对教师的学术资本的差异性来进一步探究学缘结构对学术资本的影响, 下面分 析不同学缘关系教师的学术资本均值（表3）。

表3 不同学缘教师学术资本均值

\begin{tabular}{cc}
\hline 学缘 & 平均值 \\
\hline 本科 & 259.2376 \\
硕士 & 21.2997 \\
博士 & 43.4826 \\
本硕 & 28.1465 \\
本博 & 2.8244 \\
硕博 & 61.0149 \\
本硕博 & 76.0823 \\
均不是 & 21.475 \\
\hline
\end{tabular}

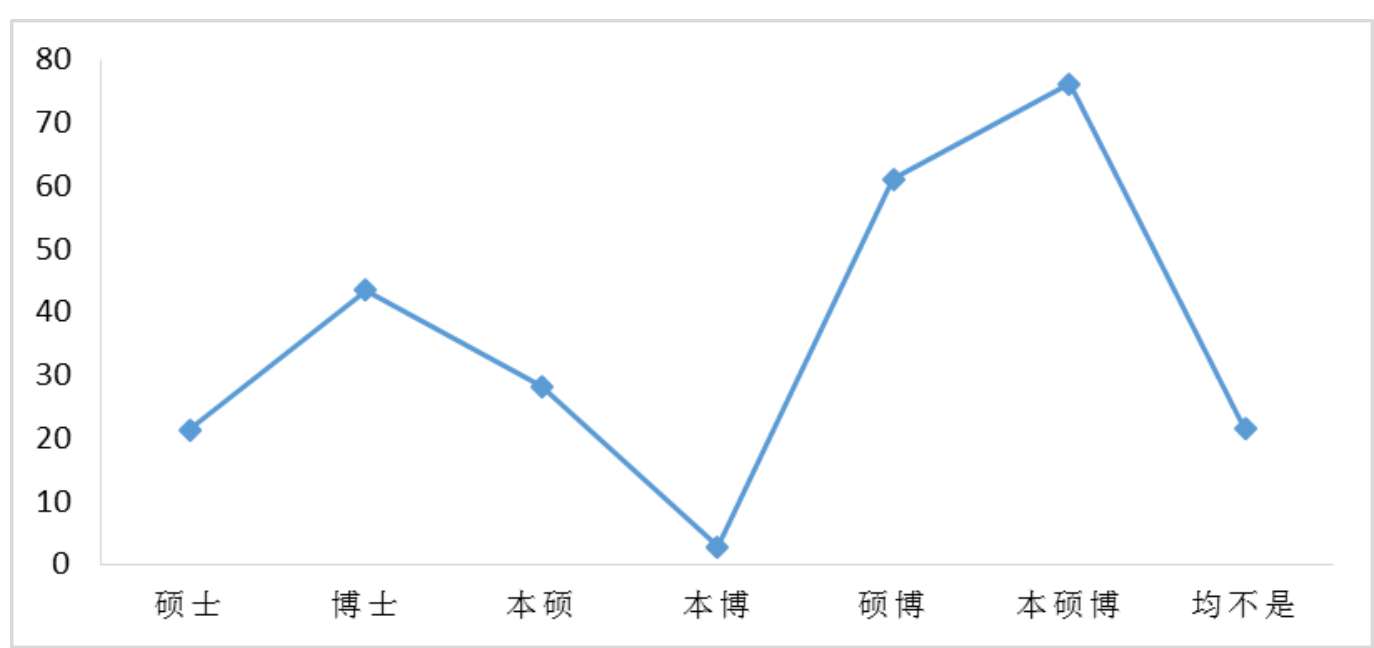

图1 不同学缘教师学术资本均值

因为具有本科学缘教师样本数量太少, 且存在异常值, 因此不考虑本科学缘的数据。由 上表可知, 具有本硕博学缘关系的教师和具有硕博学缘关系的教师学术资本所获得个人学术 资本最高, 这很符合中国的人情关系社会现状, 在本校接受本硕博三个阶段的教育, 校内的 教师合作关系更为紧密, 有学缘背景的教师更容易在校内获得学术资源。相反, 不具有任何 学缘关系的教师所获得的学术资本均值较低, 意味着没有学缘关系的教师获得较多学术资源 的可能性较低（图1）。

\section{3. 研究结论及不足}

通过对教师学术合作网络中学术资本的分析, 更进一步研究了各因素对学术资本的影响。 职称在一定程度上可以代表一个教师的学术水平, 教授的学术资本高于副教授和讲师, 虽然 副教授以第一作者身份发表的论文数量要胜于教授, 说明教授的学术资源较广, 善于与别人 合作进行学术研究。教师所获得的最高学位对其今后的学术研究有一定的影响, 本科对教师 的学术道路影响较小, 硕士是学术的萌芽阶段对学术资本有一定的影响 [7], 而博士是教师独 立学术的开始, 会对今后的学术资本有深远的影响。工科专业相对于其他专业学术资本更大, 尤其是在国外发表论文数量比较多, 说明专业对学术资本的影响比较大。相比于无学缘关系 的教师, 有学缘关系的教师学术资本并无太大的优势, 拥有硕博学缘关系的教师学术资本较 高, 是否拥有本科学缘对教师的学术资本并无大的影响。

由于受条件所限, 本文的研究有一定的局限性。首先, 本文所选数据是基于同一所学校 内的样本, 结论是否可以外推以及是否反映长期趋势尚需更多实证研究。其次, 本文用论文 
数量代表教师的学术资本, 只注重量, 并没有考虑论文引用率的因素。学术资本还应考虑教 师的专利和专著等因素。

\section{Acknowledgments}

中央高校基本科研业务费专项资金（2015jbwy012）,北京市支持中央在京高校共建项目 （B13H100050）资助。

\section{References}

[1] Yan Yan. The Academic Research Productivity of Inbred Faculty-Case Study of S Medical College [D]. Central South University, 2008.

[2] Li Ma. On the flow of talents in Colleges and universities from the perspective of "learning edge structure" [J]. Journal of South-central University for Nationalities (Philosophy and Social Science, 2001, 02: 124-125.

[3] Yuan Chen, Fengqiao Yan. The Survey and Analysis of Educational Backgrounds and Career Paths of Faculty in Higher Education Institutions in Beijing [J]. Higher Education (Research \& Evaluation, 2008, 03: 83-96.

[4] Daoyu Liu. Contain the close breeding of university faculties [J]. Journal of Higher Education, 2006 (11): 56-59.

[5] Rong Hu. Study on the factors of network and its influence Chinese weddings and funerals in rural residents [J]. Sociological Review of China, 2013, 03: 49-58.

[6] Wei Jianwen \& Zhao Yandong. Power or prestige? The argument and verification of the measurement of social capital [J]. Sociological Studies, 2011, 03: 64-83+244.

[7] Zhang Jiping, Dong Zefang, Huang Jianxiong. Comparative study of Chinese and foreign related structure strength of inbreeding coefficient of teachers in Colleges and Universities [J]. Higher Education Development and Evaluation, 2011, 06: 93-99+137. 